\title{
PREVALENCE OF PARASITIC INFECTIONS ON CULTURED NILE TILAPIA, OREOCHROMIS NILOTICUS (LINNAEUS, 1758) IN BONG COUNTY, LIBERIA
}

\author{
S. Addo*, S. Mullah, P. K. Ofori-Danson, S. K. K. Amponsah And J. O. Nyarko \\ (S. A., S. M., P. K. O-D. \& J. O. N.: Department of Marine and Fisheries Science, Univer- \\ sity of Ghana, Legon, Accra, Ghana; S. K. K.: Department of Fisheries and Water Re- \\ sources, University of Energy and Natural Resources, Sunyani, Ghana). \\ *Corresponding author's email: samuel.amponsah@uenr.edu.gh
}

\begin{abstract}
This study investigated the prevalence rate, relative abundance and mean intensity of parasites infecting cultured Nile tilapia Oreochromis niloticus L. in three fish farms, Gbarnga, Warta and CARI in Bong County, Liberia. Organs from thirty fish samples were examined from September 2016 to February 2017, along with water quality parameters. Results showed the occurrence of seven parasites including protozoans, monogeneans, digeneans, cestodes, hirudineans, nematodes and crustaceans which were organ specific in terms of infection. The prevalence of the parasites varied seasonally, with the highest numbers occurring in November-January. The low prevalence rate, relative abundance and mean intensity of the parasites showed no threat to fish farmers in Liberia. All the water quality parameters were at desirable levels for the culture of the fish except nitrite, which was beyond the threshold for sustainable fish culture. It is therefore concluded that although parasitic infections in the three farms in the Bong County were low, best farm management practices are essential.
\end{abstract}

Keywords: Nile tilapia, fish parasites, water quality, prevalence rate, relative abundance

\section{Introduction}

Tilapia is second only to carps as a farmed food fish (FAO, 2005). Tilapia is widely grown and exported to high value markets for sale (FAO, 2014). From 2011-2012, tilapia production increased from 3.5 to 4.2 million metric tonnes globally and expected to reach 5 million metric tonnes in 2015 (FAO, 2016). China is the highest producer with 1.8 million metric tonnes in 2015 followed by Indonesia and Egypt with 1.1 million metric tonnes and 0.8 million metric tonnes, respectively (FAO, 2014). According to FAO Fish Statistics (2015), 10 billion metric tonnes of cultured tilapia was sold globally in 2014. In Liberia, fish provides about $65 \%$ animal protein in the diet of the average citizen with a per capita consumption of $5 \mathrm{~kg}$ per annum, which is far below the global average of $19 \mathrm{~kg}$ per annum (FAO, 2016). The fisheries sector has contributed 12 percent to agricultural GDP and 3.2 percent to national GDP (BNF, 2014). However, FAO (2014) noted that the contribution of aquaculture as a subsector is insignificant because it is still in its emerging stages and limited, occurring mostly as smallscale freshwater ponds. The sub-sector has a total of 1704 earthen ponds with a total surface area of 113.9 ha distributed in 160 communities nationwide, but these produce only 40 metric 
tonnes of fish per year (BNF, 2014). The low productivity has been attributed to the lack of technical knowhow in the subsector, lack of quality feed on the market, poor quality and/ or non-availability of fingerlings, and limited budgetary allotment by the government of Liberia to the aquaculture subsector (BNF, 2014). Several factors contribute to low productivity of the Nile tilapia especially in Sub-Saharan Africa, and one most significant factor which is often ignored, is the prevalence of parasitic infections and diseases. This is because fish and other vertebrates serve as either intermediate or final hosts to a number of parasitic agents, resulting in their stunted growth, and hence low volume of production in fish farms (Agbeko et al., 2014). The incidence of fish parasites could be as a result of high stocking density, poor conditions of farming, lack of proper husbandry and stress (George, 2002). Poor water quality and lack of quality nutrition can also cause parasitic disease outbreaks (Edema et al., 2008). Many fish species have been found to harbour protozoans in particular, and many other parasites on their skin, gills, mouth, eyes and on some internal organs (George, 2002). Parasitic infestation of fish will eventually lead to a reduction in their production since parasites affect the physical well-being of fish (Osuigwe et al., 2011), compromise the immunity of the fish and create opportunity for secondary infestation by bacteria, fungi and viruses. The culture of tilapia by small scale farmers in Liberia, could therefore be threatened by the presence of fish parasites as a result of husbandry practices. Unfortunately, there is no existing information on parasitic infestations of cultured Nile tilapia in the country despite the poor husbandry practices and the concomitant low production values. Thus, assessing the prevalence and abundance of parasitic agents in farmed Nile tilapia from some farms in Liberia will provide vital information for the advancement of the industry in Liberia.

\section{Experimental}

\section{Study sites}

This work was carried out in Bong County, which is situated in the north-central part of Liberia (Fig. 1). Comparatively, Bong County has a total number of 120 aquaculture farmers which enables the county to maintain the higher fish farming activities among all the 15 Counties in Liberia (BCAA, 2016). Three fish farms were selected for this study for lack of logistics, bad road network and limited funding. The area of the county measures 8,772 square kilometers. It is the third most populated county with a total of 328,919 inhabitants in Liberia (LIGIS, 2008). The county was established in 1964 and currently has an emerging aquaculture industry with more than 100 fish farmers. The Central Agricultural Research Institute (CARI) is also located in Suakoko district, which is one of the twelve districts in the county. It is bordered by 7 counties and its northeast part also borders the Republic of Guinea. 


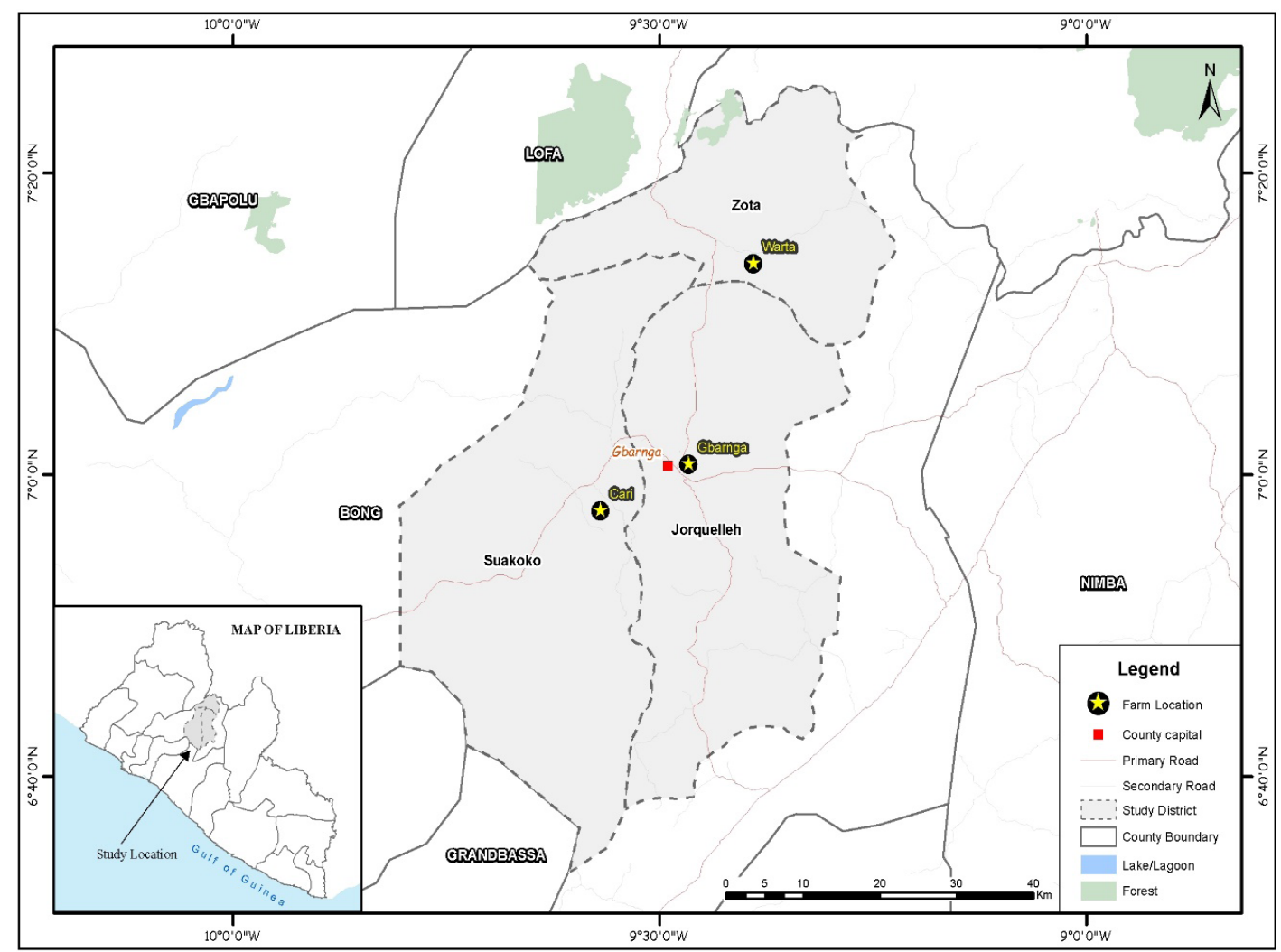

Fig. 1: A map of Liberia showing the Bong County where the study was conducted.

\section{Data collection}

\section{Fish sampling}

A total of 180 samples of mixed-sex Nile tilapia were collected in the morning using cast net from three fish farms - Gbarnga, Warta and CARI - each for a period of six months (September 2016-February 2017). Fish samples were preserved on ice in an ice chest and transported to the laboratory for parasitic examination at the College of Agriculture and Sustainable Development, Cuttington University, Suakoko, Liberia. Dissolved oxygen and water temperature were measured in-situ while $\mathrm{pH}$, ammonia, nitrite and nitrate were measured ex-situ at two-week intervals in each farm.

\section{Parasitological studies}

Sampled fish were thoroughly examined for both ectoparasites and endoparasites. For ectoparasites, the external surface of the fish was examined using light microscope (40x-100x magnification) (Micrometer, Fisher Scientific, Pittsburgh, PA, USA) and a dissecting microscope (Vista Vision, USA), especially, areas around the nostril, operculum, fins, and the buccal cavity were examined for external parasites. Gills were cut with the tips of a sharp scissor and removed with forceps and examined entirely under the dissecting microscope at a magnification of 40x - 100x. Gill smears was also prepared and observed under a light microscope according to Aloo 
et al. (2004). The exterior surface of the fish was observed for ectoparasites and injuries. The skin was scraped and wet mount of mucus was placed on clean glass slide and examined with light microscope. The buccal cavity and the eyes of the fish were washed in separate Petri dishes and examined under a dissecting microscope. The operculum was removed and observed under the dissecting microscope. In the case of endoparasites, each specimen was dissected for examination of parasites within its internal organs. The gut was removed, placed in a Petri dish containing some physiological saline solution and divided into 3 sections; foregut, midgut and hindgut. Some organs such as the gonads, gall bladder, heart, swim bladder and the liver were also examined (Aloo et al., 2004).

\section{Parasites identification}

The identification of parasites collected was performed based on the distinctive body shapes and the morphological features of the specimen retrieved and those provided by Florio et al. (2009). Furthermore, identification key by Paperna (1996) was used for identifying major taxa of adult and larval parasites of fish was extensively used. The major features that were used to identify their parasites were morphological features of the parasites such as shape and size and preference sites in the fish host. Taxonomic identifications were mostly limited to genus level because the fish harbours mostly larval stages of parasite and could not be distinguished to species level morphologically. Parasites extracted from sampled fish were preserved in $70 \%$ alcohol for later identification. Different methods of fixation for observing fish parasites followed the procedure illustrated by Stewart and Bernier (1999) since different parasites require different methods of fixation. The fish body was divided into two parts; (i) anterior part (head, eyes and gills) and (ii) posterior part (all fins and rest of the body) to detect the infection site. For each group of parasites, the site(s) of infection or attachment on the fish were noted and recorded during the laboratory analysis.

\section{Data analysis}

The prevalence, abundance and intensity of infection of various parasites were calculated using formulae by Das et al. (2014) as follows:

a. Prevalence indicates the proportion or percentage of infected fish.

Prevalence of infection $\%=$
$\frac{\text { Total no. of infected fishes }}{\text { Total no. of fish examined }} \times 100$

b. Abundance shows number of parasites recovered.

Abundance $=$

$\underline{\text { Total no. of parasites recovered }} \times 100$

Total no. of fish examined

c. Mean intensity indicates the mean of the number of parasites.

Mean intensity of infection $=$

$\frac{\text { Total no. of parasites recovered }}{\text { Total no. of infested fish }} \times 100$

Statistical analysis

Mean of parasitic prevalence among the sampling sites was subjected to ANOVA, to test for significance level using an alpha value of 0.05 . Additionally, post hoc analysis specifically Tukey test was applied to establish which groups of sampling sites exhibited significant differences based on mean comparison. The SPSS statistical tool (version 23) was used to run the ANOVA and subsequently the Post hoc analysis. Distinction in the prevalence of major parasites with sampling station as well as differences in intensity of parasitic infestations are illustrated by graphs. Graphs and tables were generated using Microsoft excel 2013. 


\section{Results}

\section{Parasitic infestations}

Parasite composition in cultured Nile tilapia Fish parasites belonging to seven broad groups were isolated from $O$. niloticus cultured in three fish farms A (Gbarnga), B (Warta) and C (CARI) in Bong County, Liberia (Figs. 2, 3 and 4$)$.

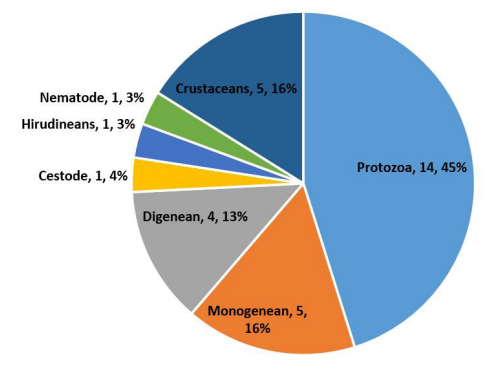

Fig. 2: Percentage of parasitic group composition in cultured O. niloticus for Farm A in Bong County, Liberia.

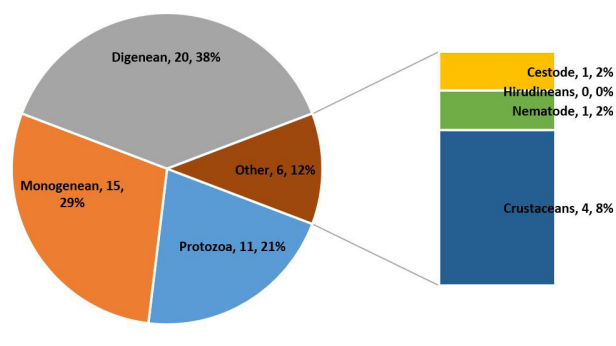

Fig. 3: Percentage of parasitic group composition in cultured O. niloticus for Farm B in Bong County, Liberia.

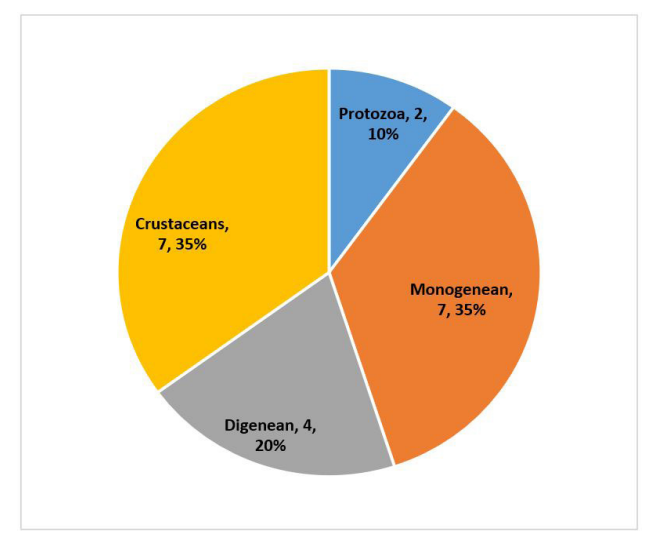

Fig. 4: Percentage of parasitic group composition in cultured O. niloticus for Farm C in Bong County, Liberia.

The parasitic groups were Protozoans, Monogeneans, Digeneans, Cestodes, Hirudinean, Nematodes and Crustaceans. From Fig. 3, there were more protozoans $(10 \%-45 \%)$, monogeneans $(16 \%-35 \%)$ and digeneans $(13 \%-38 \%)$ than the rest of the parasitic groups. Fish parasites with the lowest representation was the Hirudinean which was only found in Farm A (3\%). However, dominance of parasites was specific with protozoans $(45 \%)$ dominating Farm A, digeneans (38\%) in Farm B and crustaceans $(35 \%)$ in Farm C. Specifically, for Farm A, all the assessed fish parasites were found in the investigated organs with the exception of the liver. From Table 1 For Farm A, the skin recorded high number of protozoa $(33.3 \%)$, crustacea $(33.3 \%)$ and monogeneans $(26.7 \%)$. The gill recorded high number of protozoa 
$(90 \%)$ while the gut had more amount of digeneans $(66.7 \%)$. However, the remaining parasites were either absent $(0.0 \%)$ or found in small amounts $(6.7 \%-16.7 \%)$. At Farm B, fish parasites were found in all the investigated organs. The skin recorded high number of crustaceans (33.3\%) and monogeneans $(66.7 \%)$.

TABLE 1

Parasitic groups (\%) and organs infested in $O$. niloticus from Farm $A$.

\begin{tabular}{lcccc}
\hline Parasitic & \multicolumn{5}{c}{ Infested Organs (\%) } \\
& \multicolumn{5}{c}{ Liver } \\
\hline Group & Skin & Gill & Gut & 0.00 \\
Protozoans & 33.33 & 90.00 & 0.00 & 0.00 \\
Monogeneans & 26.67 & 10.00 & 0.00 & 0.00 \\
Digeneans & 0.00 & 0.00 & 66.67 & 0.00 \\
Cestodes & 0.00 & 0.00 & 16.67 & 0.00 \\
Hirudineans & 6.67 & 0.00 & 0.00 & 0.00 \\
Nematodes & 0.00 & 0.00 & 16.67 & 0.00 \\
Crustaceans & 33.33 & 0.00 & 0.00 & 0.00 \\
Total & 100 & 100 & 100 & 100 \\
\hline
\end{tabular}

The gill revealed high number of protozoa $(61.1 \%)$ and monogeneans $(38.9 \%)$ while the gut and liver had more amount of digeneans $(90.5 \%$ - 100.0\%) (Table 2). However, the remaining parasites were either absent $(0.0 \%)$ or found in small amounts (4.8\%). Fish samples from Farm $\mathrm{C}$ also had parasites on all investigated organs.
TABLE 2

Parasitic groups (\%) and organs infested in $O$. niloticus from Farm $B$.

\begin{tabular}{lcccc} 
Parasitic & \multicolumn{3}{c}{ Infested Organs (\%) } \\
& & & & \\
Group & Skin & Gill & Gut & Liver \\
Protozoans & 0.00 & 61.11 & 0.00 & 0.00 \\
$\begin{array}{l}\text { Monogene- } \\
\text { ans }\end{array}$ & 66.67 & 38.89 & 0.00 & 0.00 \\
$\begin{array}{l}\text { Digeneans } \\
\text { Cestodes }\end{array}$ & 0.00 & 0.00 & 90.48 & 100.00 \\
Hirudineans & 0.00 & 0.00 & 4.76 & 0.00 \\
Nematodes & 0.00 & 0.00 & 4.76 & 0.00 \\
Crustaceans & 33.33 & 0.00 & 0.00 & 0.00 \\
Total & 100 & 100 & 100 & 100 \\
\hline
\end{tabular}

From Table 3, the skin recorded the highest number of monogeneans $(83.3 \%)$ while the gill revealed high number of crustaceans $(70 \%)$. The gut had more digeneans $(100 \%)$ while the liver had no parasites at all $(0.0 \%)$. All other parasites were either absent $(0.0 \%)$ or found in low numbers $(10.0 \%-20.0 \%)$.

TABLE 3

Parasitic groups (\%) and organs infested in $O$. niloticus from Farm $C$

\begin{tabular}{lcccc}
\hline Parasitic & \multicolumn{4}{c}{ Infested Organs (\%) } \\
& & & & \\
Group & Skin & Gill & Gut & Liver \\
Protozoans & 16.67 & 10.00 & 0.00 & 0.00 \\
Monogene- & 83.33 & 20.00 & 0.00 & 0.00 \\
ans & 0.00 & 0.00 & 100.00 & 0.00 \\
Cestodes & 0.00 & 0.00 & 0.00 & 0.00 \\
Hirudineans & 0.00 & 0.00 & 0.00 & 0.00 \\
Nematodes & 0.00 & 0.00 & 0.00 & 0.00 \\
Crustaceans & 0.00 & 70.00 & 0.00 & 0.00 \\
Total & 100 & 100 & 100 & 100 \\
\hline
\end{tabular}


Prevalence, relative abundance and mean intensity of parasitic infestation

Fig. 5, 6, 7 and 8 present the prevalence, abundance and intensity of parasite infestation of $O$. niloticus from the three farms. From Farm A, the prevalence rate ranged from $6.7 \%$ to $20 \%$, with highest percent prevalence occurring in November and January. The prevalence rate ranged from $6.7 \%$ to $46.7 \%$ for Farm B and the highest rate recorded in November. For Farm C, it ranged from $3.3 \%$ to $20 \%$; with December having the highest percentage. Prevalence rate generally were high in all the farms from November to January (Fig. 5). Total prevalence rate of parasitic infestation at the three farms was in a descending order; Farm B (22.8\%) > Farm A $(15 \%)>$ Farm C (10\%) as shown in Fig. 6.

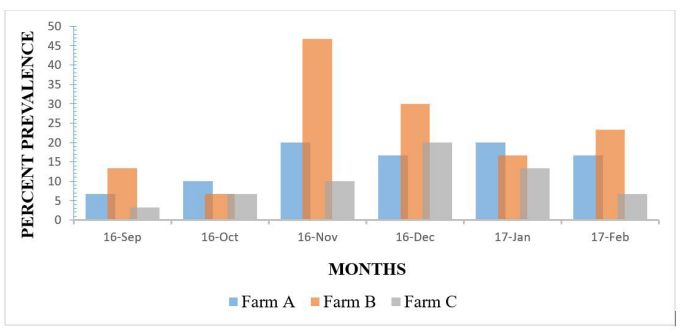

Fig. 5: Monthly prevalence rate of parasites infestation of $O$. niloticus at the three farms.

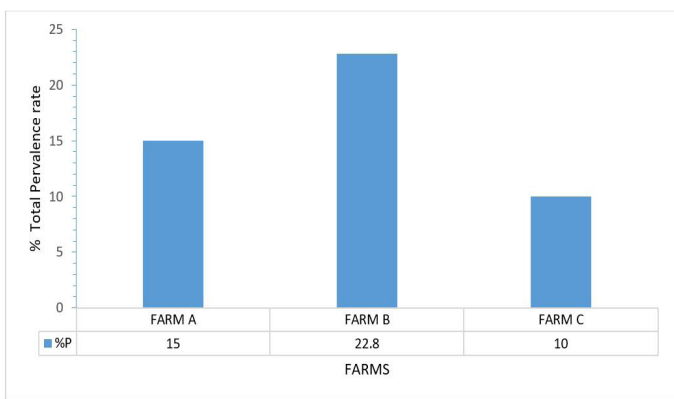

Fig. 6: Total prevalence rate of parasites infestation (\%) of O. niloticus at the three farms.
The lowest relative abundance record of parasites for Farm A occurred in September and October at 0.1 and the highest in January at 0.3. For Farms B and C, the lowest were in October 0.07 and September 0.03 respectively, and were most abundant in December at 0.6 and 0.27 concomitantly. The trend in abundance was similar to prevalence rate peaking from November to January (Fig. 7).

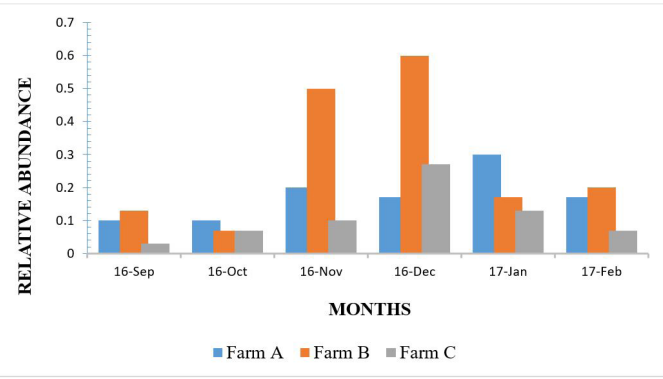

Fig. 7: Monthly relative abundance of parasite infestation of $O$. niloticus at the three farms.

The mean intensity of parasite infestation as presented in Fig. 8 peaked in September and January in Farm A. It was highest in Farms $\mathrm{B}$ and $\mathrm{C}$ in December. It did not show any peculiar trend but December appeared as the peak month.

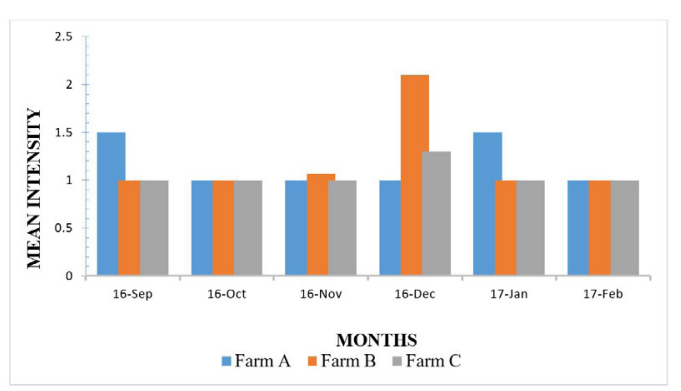

Fig. 8: Monthly mean intensity of parasite infestation of $O$. niloticus at the three farms.

Overall, the means of all the parasite infestation parameters were low, values of the mean $\%$ 
prevalence, mean intensity, mean abundance obtained from farms A, B and C were $(15 \%$, $22.8 \%, 10 \%, 1.15,1.27,1.11$ and $0.17,0.29$,
0.11 ) respectively, based on the total number of fish examined per farm and the number of fish infested (Table 4).

TABLE 4

Total percent prevalence, mean intensity and relative abundance of parasites infesting $O$. niloticus cultured in three farms in Bong County, Liberia.

\begin{tabular}{ccccccc}
\hline Farm & $\begin{array}{c}\text { No. of fish } \\
\text { examined }\end{array}$ & $\begin{array}{c}\text { No. of fish } \\
\text { infected }\end{array}$ & $\begin{array}{c}\text { No. of } \\
\text { parasites }\end{array}$ & $\begin{array}{c}\text { Mean \% } \\
\text { prevalence }\end{array}$ & Mean intensity & $\begin{array}{c}\text { Mean } \\
\text { abundance }\end{array}$ \\
A & 180 & 27 & 31 & 15.0 & $1.15 \pm 0.11$ & $0.17 \pm 0.03$ \\
B & 180 & 41 & 52 & 22.8 & $1.27 \pm 0.18$ & $0.29 \pm 0.09$ \\
C & 180 & 18 & 20 & 10.0 & $1.11 \pm 0.05$ & $0.11 \pm 0.03$ \\
\hline
\end{tabular}

Water quality at the farms

During the period of study, mean water temperature ranged from $26.63 \pm 0.61{ }^{\circ} \mathrm{C}$ in Farm B to $28.13 \pm 0.33{ }^{\circ} \mathrm{C}$ (Table 5), in Farm C. Farm A recorded a mean value of $27.13 \pm$ $0.83{ }^{\circ} \mathrm{C}$. There were no significant differences $(\mathrm{p}>0.05)$ among the mean temperature of water for all the farms. However, significant difference $(\mathrm{p}<0.05)$ occurred between mean temperature and parasite intensity in all the farms. In all the farms, mean temperature related significantly to parasite intensity $(\mathrm{p}$ $=4.38 \mathrm{E}^{-10}$ Farm A; $\mathrm{p}=2.58 \mathrm{E}^{-12}$ Farm B; $\mathrm{p}=$ $7.39 \mathrm{E}^{-9}$ Farm $\left.C\right)$ and abundance $\left(\mathrm{p}=6.06 \mathrm{E}^{-9}\right.$ Farm A; $p=6.73 \mathrm{E}^{-11}$ Farm B; $\mathrm{p}=1.03 \mathrm{E}^{-12}$ Farm C). The relationship with parasite prevalence rate was similarly significant except in Farm $\mathrm{B}(\mathrm{p}=0.003$ Farm $\mathrm{A} ; \mathrm{p}=0.538$ Farm $\mathrm{B} ; \mathrm{p}=$ 0.001 Farm C).

TABLE 5

Mean water quality parameters of the three farms in comparison with the desirable and tolerance levels for the growth of Nile tilapia.

\begin{tabular}{llllll}
\hline Parameter & Farm A & Farm B & Farm C & $\begin{array}{l}\text { *Tolerance } \\
\text { level }\end{array}$ & *Desirable level \\
\hline Temperature $\left({ }^{\circ} \mathbf{C}\right)$ & $27.13 \pm 0.83$ & $26.63 \pm 0.61$ & $28.13 \pm 0.33$ & $12-32{ }^{\circ} \mathrm{C}$ & $26-320 \mathrm{C}$ \\
$\begin{array}{l}\text { Dissolved Oxy- } \\
\text { gen (mg/L) }\end{array}$ & $2.51 \pm 0.55$ & $2.95 \pm 0.39$ & $3.55 \pm 1.39$ & $2-8 \mathrm{mg} / \mathrm{L}$ & $3-5 \mathrm{mg} / \mathrm{L}$ \\
$\mathbf{p H}$ & $6.63 \pm 0.31$ & $6.52 \pm 0.20$ & $6.79 \pm 0.29$ & $5-10$ & $6.5-85$ \\
Nitrate (mg/L) & $0.13 \pm 0.05$ & 0.00 & 0.00 & $0-3 \mathrm{mg} / \mathrm{L}$ & 0
\end{tabular}


$\begin{array}{llllll}\text { Nitrite (mg/L) } & 4.58 \pm 1.49 & 0.00 & 0.00 & 0.1-0.2 \mathrm{mg} / \mathrm{L} & 0\end{array}$

Ammonia (mg/L) $\quad 0.08 \pm 0.03 \quad 0.00 \quad 0.00 \quad 0.0125 \mathrm{mg} / \mathrm{L} \quad<0.1$

*Tolerance and desirable levels adopted from (Anani, 2015; Agbo, 2008; Swann, 1997; Hussain, 2004)

Mean dissolved oxygen (DO) at the farms during the study period ranged from $2.51 \pm$ $0.55 \mathrm{mg} / \mathrm{L}$ to $3.55 \mathrm{mg} / \mathrm{L}$ (Table 5). The DO for Farms B and C were significantly higher $(p=0.001)$ than Farm A. There was no significant difference between Farm B and C $(p=0.056)$. Comparison of the Mean DO with parasite intensity from Farm B and C showed significant difference with alpha values $\mathrm{p}=$ 0.003 and $\mathrm{p}=0.007$ respectively. Statistical testing of the mean DO against abundance and prevalence from the three farms also showed significant differences: for abundance: $\mathrm{p}=$ $0.029, \mathrm{p}=7.5 \mathrm{E}^{-6}$ and $\mathrm{p}=0.002$ for Farm $\mathrm{A}$, $\mathrm{B}$ and $\mathrm{C}$ respectively; and for prevalence: $\mathrm{p}=$ 0.002 Farm A, $p=0.016$ Farm B and $p=0.042$ Farm C.

Mean $\mathrm{pH}$ varied in the range 6.52 \pm 0.20 (Farm B) - $6.79 \pm 0.29$ (Farm C). Farm A showed a pH value of $6.63 \pm 0.31$. Mean $\mathrm{pH}$ among the farms did not show any difference significantly $(p>0.05)$. No significant difference $(p=0.245)$ was found between the mean $\mathrm{pH}$ and prevalence rate for Farm C. However, there were significant differences between prevalence rate and $\mathrm{pH}$ in Farms A and B ( $p=0.013$ and $p=0.035)$ correspondingly. The mean $\mathrm{pH}$ compared with the intensity and abundance of fish parasites showed significant differences. For intensity $\left(\mathrm{p}=1.3 \mathrm{E}^{-11}\right.$ Farm $\mathrm{A}, \mathrm{p}=4.29 \mathrm{E}^{-8}$ Farm $\mathrm{B}$ and $\mathrm{p}$ $=7.7 \mathrm{E}^{-10}$ Farm $\left.\mathrm{C}\right)$ and abundance $\left(\mathrm{p}=4.21 \mathrm{E}^{-9}\right.$ Farm A, $p=3.43 \mathrm{E}^{-13}$ Farm B and $\mathrm{p}=2.77 \mathrm{E}^{-9}$ Farm C).

In general, nitrate, nitrite and ammonia were present only in Farm A (Table
5). Farms $B$ and $\mathrm{C}$ recorded $0.00 \mathrm{mg} / \mathrm{L}$. The mean concentration of nitrite was very high in the farm $(4.58 \pm 1.49)$ and was above the range suitable for good growth of the Nile tilapia. Statistical analysis showed significant differences between the mean nitrate and parasites intensity and between nitrate and prevalence $(\mathrm{p}=0.000$ and $\mathrm{p}=0.001$ respectively) for Farm A. However, there was no significant different between the mean nitrate and parasites abundance from Farm A $(p=0.177)$. There were significant differences between the mean nitrite and parasites intensity and between nitrite and prevalence ( $p$ $=0.000$ and $p=0.001$ respectively) for Farm A. Comparison of the mean ammonia values with parasites intensity and abundance from Farm A showed no significant differences ( $\mathrm{p}=$ 0.315 and $p=0.209$ respectively); whiles there was significant difference between the mean ammonia and prevalence rate $(p=0.022)$ in the same farm.

\section{Discussion}

Nile tilapia cultured in three fish farms located in the Bong County in Liberia were found infested with some protozoans, monogeneans, digeneans, cestodes, hirudineans, nematodes and crustaceans. These parasites infested the skin, gills, liver and the gut of fish and can be categorized into ectoparasites and endoparasites. Parasites that are located within the flesh and cavities of the host organism are termed as endoparasites, while parasites that are located on the external surfaces of a host organism are ectoparasites. In this study, 
the protozoan, monogenean, hirudinean and crustacean groups were on the skin and/or gills and are classified as ectoparasites whiles the rest were either in the liver and/or gut and can be termed endoparasites. Overall, the higher number of ectoparasites as compared to endoparasites recorded from the farms could be a result of poor management practices. Other research done have revealed that the high ratio of ectoparasites to endoparasites on cultivated fish ponds signified poor farming practices and environmental conditions (Klinger \& Floyd, 2002; Barker \& Cone, 2000).

During pond fish culture, fish are introduced into the ponds as fingerlings or juveniles, which are more susceptible to infection than adult fish. Hence infestation might have occurred during their early stages in the culture facilities. According to Kearn (2004) \& Wiegertjes \& Flik (2004), the high number of parasites in adult fish maybe due to initial poor hatchery conditions, which provide excellent breeding environments for ectoparasites as intra population transmission rates become high in such facilities. In addition, fingerlings have under-developed immune systems, which render the natural repellant ability of the skin and gill surface non-functional and results in increased susceptibility to ectoparasites which in many cases serve as mechanical vectors to viral and bacterial infections (Barker \& Cone, 2000; Paperna, 1996). When such fingerlings are used in stocking either a newly established or already existing farm, the parasites may be transmitted into the ponds to cause an outbreak. Ramudu et al. (2013) in their study on prevalence of monogenean parasites on Indian Major Carps in Bheries of West Bengal reported that infected brood stocks might also transfer ectoparasites from farm to farm when their fingerlings are used to stock uninfected ponds.
The diverse number of parasitic groups encountered in Nile tilapia from Farm A as compared to Farms B and C, could be as a result of the poor water quality observed. Farm A was an integrated farm where aside the fish ponds, there was a piggery and a poultry facility. Ponds were treated with wastes from these facilities as organic fertilizer, which raised the levels of ammonia and nitrite above the desirable limits. The use of the animal manure might have accounted for the relatively high percent prevalence (15\%), relative abundance $(0.17)$ and mean intensity (1.15) of parasites in comparison with farm C. Farm B had relatively higher percent prevalence, relative abundance and mean intensity of parasites than Farm A. This was probably because Farm B draws water into the culture ponds from a nearby stream without any filtering. Non-filtering of water for culture practices could lead to the introduction of unwanted organisms including parasitic agents into the culture facilities. Thus, the differences in parasitic load and diversity in fish cultured from the three farms might be largely influenced by environmental disparities. Awa et al. (1996) suggested that differences in parasitic infestations of fish may be due to ecological differences and the presence or absence of source of infestation. According to Lafferty (2008) environmental alteration, particularly habitat degradation by anthropogenic contaminants and oceanographic variations induced by climatic change, can influence parasitic host interactions.

Nnadi et al. (2011) reported that when environmental parameters change, fishes become stressed, which gives parasites the advantage to reach to a host for their survival. The reported desirable level of temperature requirements for $O$. niloticus by Anani (2015), Agbo (2008), Swann (1997) \& Hussain (2004) did not differ from the range obtained in this study $\left(26-32{ }^{\circ} \mathrm{C}\right)$. Thus, the temperature 
recorded from the three farms fall within the desirable levels for $O$. niloticus. The nitrate concentration reported from the three farms were in the tolerance range $(0-3 \mathrm{mg} / \mathrm{L})$ for $O$. niloticus and in agreement with the reports by Anani (2015); Agbo (2008); Swann (1997); Hussain (2004). Moreover, most of the values recorded from the farms were nil, an indication that there was zero trace of nitrate which is desirable for the species of concern. However, the nitrite concentrations were within the safe zone $(0.00 \mathrm{mg} / \mathrm{L})$ for farms $\mathrm{B}$ and $\mathrm{C}$. The ammonia levels reported from these farms were within the desirable range of $(<0.1 \mathrm{mg} / \mathrm{L})$ for $O$. niloticus in Liberia is in agreement with reports by Anani (2015); Meiludie (2013); Agbo (2008). The pH is one of the environmental parameters that determine the lifespan of fishes. The values obtained for the farms in this study were within the acceptable range of $6.5-9.0$ for the growth of Nile tilapia Anani (2015), Meiludie (2013, Agbo (2008). However, dissolved oxygen values recorded from Farm $\mathrm{A}$ and $\mathrm{B}$ were below the acceptable tolerance level $(5.0-8.0$ ppm) for O. niloticus whereas Farm C recorded DO within the desirable range (Meiludie, 2013). Khan et al. (2013) in their studies on production and economics of gift strain of tilapia (Oreochromis niloticus) in small seasonal ponds in Mymensingh, Bangladesh documented that low DO level might have not any negative effect since tilapia has high tolerance to fluctuations in environmental conditions. The afore-mentioned water quality parameters which were within the suitable range, shows that the growth, production and survival of $O$. niloticus was not affected by environmental conditions (Gupta et al., 2012). In addition, though differences in the percent prevalence, relative abundance and mean intensity of parasites infesting fish cultured at the three farms, the levels of infestation were generally low $(15 \%, 22.8 \%, 10 \%, 1.15$,
$1.27,1.11$ and $0.17,0.29,0.11)$ respectively, indicating that there were less parasites occurring on the fish. Probably, this could be due to the low stocking rate of fingerlings (3 fish $/ \mathrm{m}^{2)}$, generally practiced by fish farmers in Liberia (BNF 2007). The concentration of parasites increases on fishes with enhanced transmission rate as the results of stressful environment and the suppression of natural immunity (Amoako, 2006).

\section{Conclusions}

From this study, it was established that cultured Nile tilapia in the three farms in the Bong County in Liberia were infested with parasitic agents with infestation ranging from $3.3 \%$ to $46.7 \%$. Seven groups of fish parasites namely; protozoan, monogenean, digenean, cestode, nematode, hirudinean and crustacean were observed in fish cultured in the farms. Parasite status through further scientific studies within aquaculture farms should be taken be considered as a proxy to aquaculture development in Liberia. Furthermore, sensitization programmes for relevant stakeholders in Liberia's aquaculture industry should be promoted in order to ensure that, the best farm practices geared toward monitoring water quality daily, liming and fertilization of ponds, producing and stocking quality fingerlings from improve broodstock, regular feeding of fish with quality feeds, good sanitation, regular exchange of pond water and good source of water inflow are employed to avoid contamination of fish produced in Liberia's aquaculture.

\section{Declaration of conflict of interest}

The authors declare that there is no conflict of interest.

\section{Acknowledgements}

This work was supported by the United States Agency for International Development, 
as part of the Feed the Future initiative, under the CGIAR Fund, award number BFS-G-11-00002, and the predecessor fund the Food Security and Crisis Mitigation II grant, award number EEM-G-00-04-00013.

\section{References}

Agbeko, E., Kwarfo-Apegyah, K. \& Akongyuure, D.N. (2014). Optimization of dugout fisheries for climate Change adaptation in Northern Region, Ghana. Journal of Energy and Natural Resources Management. JENRM, 1(1), 63 - 68 .

Agbo, N. W. (2008). Oilseed Meals as Dietary Protein Sources for Juvenile Nile Tilapia Oreochromis niloticus $\mathrm{L}$. $\mathrm{PhD}$ dissertation, Institute of Aquaculture, University of Stirling, Scotland, UK. 223 - 4pp.

Aloo, P. A., Anam, R. O. \& Mwangi, J. N. (2004). Metazoan parasites of some commercially important fish along the Kenyan Coast, Western Indian Ocean. J. Mar. $\quad$ Sci. 3, 77 - 78.

Амодко, M. (2006). Infections of ectoparasites on Nile Tilapia (Oreochromis Niloticus) in aquaculture production in the Ashanti Region, Ghana. Master's Thesis, Department of Marine and Freshwater Biology, Norwegian College of Fishery Science, University of Tromso, Norway.

AnANi, F. A. (2015). Evaluation of Farm-Made and Commercial Fish Diet for Hapa Culture of Nile Tilapia (Oreochromis niloticus L) in Ghana. PhD dissertation, Department of Marine and Fisheries Sciences, University of Ghana, Legon. 216pp.

Awa, J. U., Ugumba, A. \& Odaibo, A. B. (1996). Parasites of Oreochromis nilotica of Ita Lake, Ibadan, Oyo State, Nigeria. The Nigeria Journal of Parasitology, 17,115 - 170.

BARKer, D.E. \& Cone, D. K. (2000). Occurrence of Ergasilus celestis (Copepoda) and Pseudodactylogryrus anguillae (Monogenea) among wild eels (Anguilla rostrata) in relation to stream flow, $\mathrm{pH}$ and temperature and recom- mendations for controlling their transmission among captive eels. Aquaculture 187, 261 274.

BCAA (2016). Bong County Aquaculture Association. Bong County, Liberia, unpublished.

BNF (2007). Bureau of National Fisheries. A Developing Sector: Aquaculture in Liberia. Ministry of Agriculture (MOA).

BNF (2014). Bureau of National Fisheries. Fisheries and Aquaculture Policy and Strategy: Ministry of Agriculture (MOA). 73 pp.

DAS, B. K., Kar, S. \& Kar, D. D. (2014). Studies on prevalence, abundance and intensity of Fish parasites in Monopterus cuchia. Indian J. Applied \& Pure Bio. 29 (1), 25 - 3.

EDEMA, C. U., OKAKA, C. E., OBOH, I. P. \& OKOGUB, B. O. (2008). A preliminary studyof parasitic infections of some fishes from Okhuo River, Benin City, Nigeria. Int J Biomedical Health Sciences, 4 (3), 107 - 112.

FAO (2005). Cultured aquatic species information programme. Oreochromis niloticus. Rome: FAO. (pp. 1-14).

FAO (2014). The State of World Fisheries and Aquaculture 2014. Rome. 223 pp. (also available at www.fao.org/3/a-i3720e.pdf).

FAO (2015). Food and Agriculture Organization of the United Nations. The State of World Fisheries and Aquaculture. Rome, $151 \mathrm{pp}$.

FAO (2016). Food and Agriculture Organization of the United Nations. The State of World Fisheries and Aquaculture. www.fao.org/3/a-i5555e. pdf

George, W. L. (2002). Angler's guide to fish diseases and parasites. University of George, College of Agricultural and Environmental Sciences, Circular 772, F\&A-1.

Gupta, N., Haque, M. M. \& Khan, M. (2012). Growth performance of tilapia fingerling in cage in ponds managed by Adivasi house- 
holds: An assessment through length-weight relationship. Journal of the Bangladesh Agricultural University, 10 (1), 149 - 155.

Hussain, M. G. (2004). FARMING OF TILAPIA: Breeding plans, mass seed production andaquaculture techniques. Dhaka, Bangladesh: Momin Offset Press. p. 149.

Kearn, G. C. (2004). Leeches, Lice and Lampreys: A Natural History of Skin and Gill Parasites for Fishes. Springer: the Netherlands. 432p.

Klinger, R. E. \& Floyd, R. F. (2002). Introduction to Freshwater Fish Parasites. Florida Cooperative Extension Service. Institute of Food and Agricultural Sciences. Universityof Florida. Accessed from http.//edis.Ifasufl.edu.

Khan, S., Hossain, M. \& Hossain, M. (2013). Production and Economics of Gift Strain of Tilapia (Oreochromis niloticus) in Small Seasonal Ponds. Progressive Agriculture, 19(1), 97 104. https://doi.org/10.3329/pa.v19i1.1736.

LAFFERTy, K. D. (2008). Ecosystem consequences of fish parasites. Journal of Fish Biology, 73 , $2083-2093$.

Meiludie, E. E. (2013). Comperative evaluation of growth performance and yield of four tilapia species under culture conditions. Master's thesis, Sokoine University of Agriculture. Morogoro, Tanzania.

NATIONAL POPULATION AND HOUSING CENSUS (2008). Liberia Institute of Statistics and Geo-Information services (LISGIS) pp. $1-352$.

Nnadi E, I., Awi-WaAdu, G. D. B. \& Imafidor, H. O. (2011). Association between parasitic infection and fish habitat. Journal of Research in National Development, 9 (1), 186 - 190.

Osuigwe, D. I., Okoro, V. D. C., Adaka, G. S., Obiekezie, A. I. \& Ogunji, J. O. (2011). The Parasites of Cultured and Feral Nile Tilapia (Oreochromis niloticus) in Umudike, Nigeria.

PAPERnA, I. (1996). Parasites, infections and diseases of fish in africa- an update. CIFA technical paper no. 31. FAO, Rome.

Ramudu, K. R., Dash, G. G. \& Abraham, T. J. (2013). Parasitic study of Cirrhinus mrigala (Hamilton, 1822) in selected districts of West Bengal, India. International Journal of Advanced Biotechnology and Research, 4 (4), 419 - 436.

Swann, L. D., (1997), A Fish Farmer's Guide to Understanding Water Quality, Aquaculture Extension Illinois, Purdue University, Indiana Sea Grant Program Fact Sheet AS-503.

Stewart, D. B. \& Bernier, L. M. J. (1999). Common Parasites, Diseases and Injuries of Freshwater Fishes in the Northwest Territories and NUNAVUT Other Publications in Zoonotics and Wildlife Disease. Paper 30.

Wiegertues, G. F. \& Flik, G. (2004). Host-Parasite Interactions. Garland Science/BIOS Scientific Publishers, the Netherlands.

Received 15 Dec 20; revised 24 Jun 21. 